\title{
ACELERAÇÃo: REFLEXõEs SOBRE O TEMPO NA CULTURA DIGITAL
}

\author{
Acceleration: reflexions on time and digital culture \\ Aceleración: reflexiones sobre el tiempo en la cultura digital
}

\begin{abstract}
RESUMo A obra de Harmut Rosa apresenta um conjunto de conceitos que permitem analisar as formas sociais de organização temporal. No centro desse arcabouço conceitual, encontra-se a ideia de aceleração. Ao colocar a aceleração no cerne da discussão a respeito da temporalidade na sociedade contemporânea, Rosa deslinda uma série de processos sociais importantes para uma crítica radical da sociedade atual, trazendo para o primeiro plano contradições e dessincronizações que resultam de imperativos temporais sistêmicos pouco discutidos e conceituados. Seu diagnóstico aponta para a existência de um déficit ético e político em cujo âmago se encontram imperativos temporais que impossibilitam tanto o debate político como a formação de uma experiência ética do sujeito sobre si mesmo e sobre a sociedade. A partir dos conceitos de Rosa, procuramos discutir temas como: a afirmação falaciosa de que a cultura digital é um meio propício à emancipação dos sujeitos que dela se valem, as dificuldades de promover um debate ético e político atualmente e a necessidade de trazer a dimensão temporal para a linha de frente da discussão acadêmica, procurando atualizar temas caros à Teoria Crítica da Sociedade.
\end{abstract}

PALAVRAS-ChAVE: ACELERAÇÃo. TEMPORALIDADE. TEORIA CRÍTICA DA SOCIEDADE. CULTURA DigitAL.

ABSTRACT Harmut Rosa's work presents a set of concepts that discusses the social forms of temporal organization. At the core of this conceptual framework is the concept of acceleration. By putting acceleration at the center of the discussion of temporality in contemporary society, Rosa delivers a series of important social processes to a radical critique of present-day society, showing its contradictions and desynchronizations that result from systemic time imperatives that are less discussed and conceptualized. His diagnosis points to the existence of an ethical and political deficit that came from temporal imperatives that make impossible both the political debate and the formation of an ethical experience of the subject about himself and society. From the concepts of Rosa, we seek to discuss themes such as: the fallacious assertion that digital culture is a means conducive to the emancipation of the subjects who use it, the difficulties of promoting an ethical and political debate today and the need to bring the temporal dimension To the front line of the academic discussion, seeking to

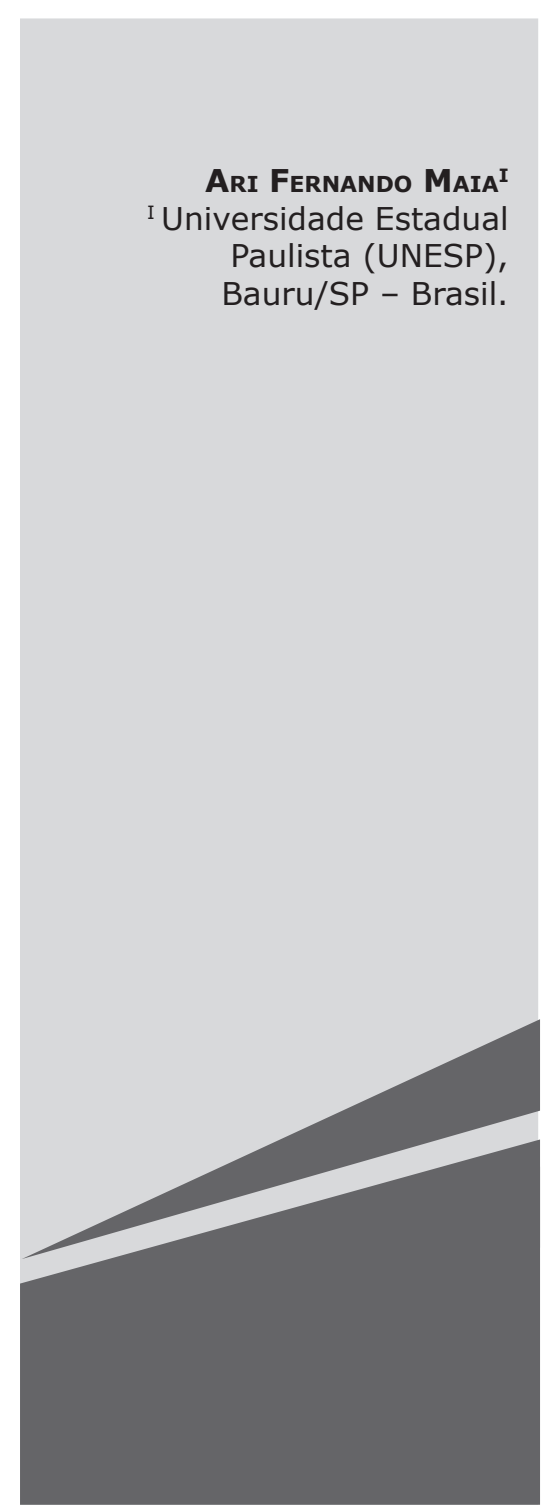


update expensive topics to the Critical Theory of Society.

KEY-WORDS: ACCELERATION. TEMPORALITY. CRITICAL THEORY OF SOCIETY. DIGITAL CULTURE.

RESUMEN El trabajo de Hartmut Rosa presenta un conjunto de conceptos que analizan las formas sociales de organización temporal. En el centro de este marco conceptual esta la idea de aceleración. Mediante la colocación de la aceleración en el centro del debate sobre la temporalidad en la sociedad contemporánea, Rosa revela una serie de procesos sociales importantes para una crítica radical de la sociedad actual, sus contradicciones principales y dessincronizaciones que resultan de los imperativos sistémicos temporales que son poco discutidas y conceptualizadas. El diagnóstico que hace es de la existencia de un déficit ético y político en cuyo corazón se encuentran las limitaciones de tiempo que impiden el debate político y la formación de una experiencia ética del sujeto sobre sí mismo y sobre la sociedad. A partir de los conceptos de Rosa, buscamos discutir temas como la afirmación falaz de que la cultura digital es un medio propicio para la emancipación de los sujetos, las dificultades de promover un debate ético y político actual y la necesidad de acercar la dimensión temporal a la vanguardia de la discusión académica, buscando actualizar temas caros a la Teoría crítica de la Sociedad.

Palavras clave: ACEleración. TemporaliDAD. TEORÍA CRÍTICA DE LA SOCIEDAD. CULTURA DIGITAL.

\section{INTRODUÇÃO}

tempo social tem ocupado vários pensadores que se preocupam em decifrar as características fundamentais da sociedade contemporânea, debatendo questões: a) a respeito da forma como deve ser identificada a atual época, abrangendo conceitos como: modernidade tardia, pós-modernidade, modernidade singular, modernidade líquida, hipermodernidade etc.; ${ }^{1}$ b) sobre como se deve interpretar e compreender

Refiro-me, por exemplo, a HARVEY (2004); JAMESON (2005); BECK (2003); POSTONE (2014), entre outros. o papel da cultura digital: como ideologia que reproduz as relações de produção ou como meio que facilita a organização de novos movimentos sociais e de resistência ao capitalismo globalizado; c) acerca da natureza do tempo, da história e de categorias do âmbito subjetivo como memória, atenção, pensamento, experiência etc., no contexto de uma avalanche de estímulos produzidos em escala industrial global e que chegam ininterruptamente aos sujeitos.

Ao lado desse amplo leque de questões, é possível identificar uma grande dispersão conceitual, o que revela a dificuldade - aparentemente relacionada às características da própria organização social em sua configuração atual - em elaborar uma teoria crítica que seja suficientemente abrangente para dar conta das características mais importantes da sociedade. Nesse sentido, a obra de Harmut Rosa ${ }^{2}$ é singularmente importante, pois procura compreender as características da sociedade atual, colocando justamente a dinâmica temporal no cerne da discussão, discernindo uma categoria fundamental: a aceleração.

\section{UMA TEORIA SOCIAL DO TEMPO}

A primeira justificativa para a escolha da aceleração como elemento que melhor define a configuração atual da temporalidade é que ela parece o traço mais notório e importante da sociedade contemporânea, sendo uma característica presente desde o início da modernidade. A segunda é que, ao contrário de outros conceitos que procuram caracterizar a modernidade como individualização, racionalização, diferenciação e dominação, a aceleração tem sido, até o momento, negligenciada. As teorias que a colocam em destaque não elaboraram teorias sobre a temporalidade abrangentes e suficientemente explicativas. O pressuposto fundamental é que a temporalidade é uma característica pervasiva da ordem social, e que as estruturas temporais subjazem e dão sentido a uma experiência histórica, à configuração da subjetividade, à política e à vida cotidiana de um modo predo-

ROSA (2003; 2015; 2010). 
minantemente inconsciente, não problematizado, não imediatamente visível.

Rosa nos apresenta a seguinte tese: "não podemos entender adequadamente a natureza e o caráter da modernidade e a lógica de seu desenvolvimento estrutural e cultural a menos que se acrescente a perspectiva temporal na análise". ${ }^{3}$ Faltaria à modernidade uma teoria sistemática da aceleração social, apesar do problema da mudança social estar presente em praticamente todos os clássicos da literatura sociológica e filosófica. ${ }^{4}$ Não é difícil constatar que a temporalidade é um traço pervasivo que medeia as grandes dimensões materiais da sociedade: sua estrutura, seus traços culturais, a relação dos homens com a natureza e a formação da personalidade e do caráter. A pretensão de Rosa é dialogar tanto com os autores clássicos da teoria social como com os autores contemporâneos da Teoria Crítica, tratando seus problemas centrais a partir de uma dimensão temporal, e dessa forma elaborar um diagnóstico da sociedade contemporânea que acabe desvelando seus traços essenciais e construindo uma teoria unificada, que permita também uma crítica radical e uma ação política eficaz.

A primeira questão problematizada em sua avaliação da modernidade é o significado do conceito de aceleração, já que o tempo físico não se altera pela ação humana. Sua análise se inicia pela constatação de que são âmbitos singulares no campo social que aceleram, mas isso não pode ser caracterizado como um processo universal e único; há processos que desaceleram ou resistem à aceleração. Além disso e, principalmente, nos processos em que evidentemente há aceleração, como nos esportes, nos fast-foods, nos computadores, nos transportes e meios de comunicação, há também contrapartidas paradoxais: apesar da maior velocidade dos automóveis atuais o transporte nas cidades acaba por se tornar mais lento em virtude dos engarrafamentos; não obstante a maior velocidade dos meios

ROSA (2003). Op cit., p. 4.

4 Rosa cita: Marx, Weber, Simmel, Durkheim e também autores das várias "gerações” da Teoria Crítica. de comunicação é duvidoso que seja possível comunicar infinitamente mais informações às pessoas; uma percepção de constante mudança social pode ocorrer em meio à permanência de estruturas essenciais da sociedade, entre outros exemplos possíveis.

Assim, para explicitar o conceito de aceleração, Rosa 5 elabora três categorias em que os vários âmbitos são especificados, e são identificados os seus elementos paradoxais: aceleração tecnológica, aceleração da mudança social e aceleração dos ritmos de vida. A primeira identifica a aceleração dos processos técnicos dirigidos a fins específicos, que produzem efeitos notórios e importantes, como a inversão da relação espaço-tempo (priorizando o segundo). Trata-se da forma mais facilmente identificável da aceleração, a mais notória e passível de quantificação. A segunda categoria identifica mudanças em atitudes, valores, modos e estilos de vida, relações sociais, hábitos, linguagens etc. Rosa ${ }^{6}$ (2010) aponta que a medição da aceleração da mudança social é desafiadora, já que envolve sempre questões filosóficas sobre a estrutura mais profunda da sociedade, mas apela ao conceito de "contração do presente" para esclarecer esse ponto, definindo-o como o horizonte de coincidência entre a experiência de vivenciar certos hábitos e valores como válidos e a expectativa de sua validade futura. Ou seja, há aceleração da mudança social quando declina a expectativa de que os hábitos, modos de vida, linguagens etc., que determinado sujeito conhece, venham a ser válidos em um tempo próximo. Historicamente, não é difícil notar, ainda segundo Rosa, 7 que o ritmo da aceleração nesse âmbito sofreu mudanças significativas: de um ritmo intergeracional, no início da modernidade, passa a geracional, na modernidade clássica, e a intrageracional na modernidade tardia.

Finalmente, a terceira categoria: a aceleração do ritmo de vida, diz respeito à crescente sensação de "falta de tempo". Refere-se,

ROSA (2005). Op. cit.

ROSA (2010). Op. cit.

IBID. 
portanto, à compressão das ações e experiências do cotidiano, e tem como contrapartida subjetiva uma sensação de "fome temporal", ou seja, uma sensação de ânsia ou necessidade de ter mais tempo e o desejo de produzir mais experiências por unidade de tempo. A categoria temporal em tela indica que têm aumentado sistematicamente o número de atos ou ações praticadas por unidade de tempo, assim como a tendência a fazer mais coisas ao mesmo tempo e reduzir as pausas e intervalos entre as tarefas realizadas. O problema central aqui é que as relações entre a aceleração dos ritmos de vida e as formas anteriores (tecnológica e da mudança social) é relativamente independente e, eventualmente, paradoxal, ou seja, não há implicação lógica ou causal entre elas.

$\mathrm{Na}$ verdade, a aceleração tecnológica deveria produzir mais tempo livre, já que o tempo necessário para escrever dez cartas é muito maior que o tempo necessário para escrever dez mensagens eletrônicas, ou o tempo necessário para um deslocamento caminhando é muito maior do que num automóvel. Rosa aponta, portanto, que a aceleração técnica deveria produzir mais tempo livre, e numa sociedade altamente desenvolvida e mediada tecnicamente, ele deveria ser abundante, já que a tecnologia permite que as tarefas necessárias sejam realizadas em menos tempo. Esse descompasso demanda uma explicação sociológica, e dele deriva uma compreensão conceitual da aceleração. Para Rosa, ${ }^{8}$ esse paradoxo indica que a quantidade de atividades (ações, operações, tarefas) cresce mais rapidamente que a taxa de aceleração tecnológica, ou seja, o desenvolvimento de novas tecnologias é visto como uma resposta ao desafio da falta de tempo que emerge no campo da atividade humana. ${ }^{9}$ Daí que, segun-

IBID.

9 Em relação ao que impulsiona a aceleração social seria fundamental remetê-la, também, à dimensão da "economia política", ou seja, explicar a necessidade de aumento crescente da quantidade de atividade numa sociedade de produção de mercadorias, o que não está no escopo deste artigo e, segundo a nossa análise, não é o único motor da aceleração de acordo do Rosa: "aplica-se o conceito de sociedade em aceleração a uma sociedade se, e somente se, a aceleração tecnológica e a crescente falta de tempo ocorrem simultaneamente". ${ }^{10}$

Assim, não se pode considerar que o motor da aceleração social é derivado essencial ou principalmente do desenvolvimento de novas tecnologias mais velozes. Inegavelmente, as três esferas se retroalimentam, em uma espiral viciosa: a intensificação da exploração do trabalhador se faz por meio de mudanças tecnológicas, que levam a mudanças em práticas sociais, que resultam em uma contração do presente e ao abandono de modos de vida consolidados, que despolitizam e isolam o trabalhador e facilitam sua exploração, que resultam em "fome temporal" e em tentativas de desaceleração funcional, e assim por diante. Assim se cria uma espécie de círculo vicioso de aceleração, em que as três esferas se alimentam mutuamente e impulsionam uma crescente celeridade nas mudanças técnicas, sociais e nos modos de vida.

Mas, claramente, não precisa necessariamente ser assim; mudanças técnicas que tornam as atividades mais velozes poderiam produzir abundância de tempo, e aí se coloca a questão das possibilidades de ação política voltadas para o tempo, que retomaremos adiante. Um elemento importante, seguindo os argumentos de Rosa, é que a crescente sensação de falta de tempo precisa ser compreendida como função de forças sociais que não estão identificadas imediatamente com o desenvolvimento tecnológico, ou seja, a tecnologia ocupa uma função ambígua em relação ao tempo.

Se a aceleração não resulta imediatamente de desenvolvimentos tecnológicos que "economizam" tempo e que subvertem a rela-

com Rosa. Quem o faz em um sentido mais radical é POSTONE (2014), cujo conceito de "tempo abstrato", advindo da crítica da economia política, permite compreender de forma mais essencial a necessidade constante de aceleração social e seu paradoxo. Essa fonte da necessidade de aceleração, contudo, não é desconsiderada por Rosa, mas ele não a considera a única, nem talvez a mais fundamental.

10 ROSA (2003), p. 10. Op cit. 
ção entre tempo e espaço, que fatores teriam impulsionado esse fenômeno temporal típico da modernidade? Segundo Rosa, ${ }^{11}$ há três fatores fundamentais que impulsionariam a aceleração: o econômico, o cultural - estrutural e o "circuito da aceleração". O primeiro aponta para a competição entre sujeitos e empresas na sociedade capitalista como um fator fundamental da aceleração: o tempo da circulação do capital é um fator crucial, de modo que o circuito de produção, distribuição e consumo constantemente acelera. ${ }^{12}$ Reduzir o tempo da produção cria vantagens concorrenciais e, além disso, o capital financeiro busca retorno o mais rapidamente possível; finalmente, estar à frente da concorrência numa perspectiva temporal é um fator essencial à sobrevivência de empresas e sujeitos.

Entretanto, Rosa chama a atenção para o fato de que o princípio da competição excede a esfera econômica: ele é o modo dominante da "distribuição" em todas as esferas da vida social na modernidade, e estabelece como critério de sucesso a realização de determinado trabalho em tempo menor. Os concorrentes devem sempre investir mais energia para seguir competindo, abreviando ao máximo o tempo necessário para realizar suas atividades, como para fazer chegar ao consumidor a mercadoria desejada.

A segunda força a produzir a aceleração seria, ainda, segundo Rosa, ${ }^{13}$ estrutural e cultural. Ela indica a existência de uma conexão entre a aceleração e os ideais dominantes da modernidade, entre eles o do progresso material contínuo e o do usufruto da vida coincidindo com um número maior de vivências.

11 IBID.

12 Sobre essa questão há análises mais aprofundadas em Harvey (2004) e Postone (2014), embora existam divergências importantes entre esses autores, principalmente em relação à leitura que fazem do conceito de valor e da circulação em Marx. A discussão dessa questão, que extrapola o âmbito analítico, primordialmente sociológico, e que acolhe também contribuições de Weber e da sociologia da cultura, de Rosa, merece uma análise mais aprofundada, em especial considerando suas consequências para as políticas de resistência.

13 IBID.
Nesse âmbito também ocorrem paradoxos, porque, de um lado, o progresso produz enormes destruições, e de outro o mundo sempre oferece mais oportunidades do que é possível vivenciar em uma vida, o que produz uma divergência entre o tempo do mundo (Weltzeit) e o tempo da vida (Lebenzeit).

No plano pessoal, a aceleração no ritmo de vida aparece aos sujeitos como uma resposta à percepção de que não se está vivendo o suficiente, de que eles se encontram em déficit em relação às possibilidades de produzir novas experiências. Isso decorre de uma "promessa hedonística" que substituiu na modernidade a promessa religiosa da vida eterna, uma espécie de resposta moderna ao problema da finitude. Efetivamente, é impossível realizá-la porque a taxa de potenciais experiências que se perde aumenta exponencialmente. ${ }^{14}$ Em outras palavras, a sociedade secularizada é orientada para a vida material, com os sujeitos visando sempre uma maior riqueza e profundidade nas suas experiências. Nesse sentido, uma vida é considerada boa quando nela se realizam mais coisas e se desenvolvem mais capacidades. A aspiração do homem passa a ser "aproveitar a vida" ao máximo, o que leva ao desejo de acelerar para poder viver mais, mas evidentemente essa expectativa conduz inevitavelmente a um grande nível de frustração.

Finalmente, Rosa chama a atenção para o que chama "circuito da aceleração" como uma força que impulsiona o aumento da velocidade das mudanças sentido pelos sujeitos. Como as sociedades modernas têm um alto grau de diferenciação funcional, isso, primeiramente, permite, depois impõe, velocidades

\footnotetext{
14 Há consequências interessantes a se retirar dessa premissa - a substituição da promessa religiosa pela promessa hedonística - para o campo da crítica à publicidade. O contínuo desejo de obter mais e viver mais intensamente estaria inserido na essência da vivência temporal da modernidade, já que o tempo não mais se desdobra em um agora terreno e um depois celeste, justificando uma perspectiva hedonista pragmática. Isso permite identificar no plano temporal, histórico-social, algo que comumente se atribui aos desejos insaciáveis do sujeito, ou aos poderes manipulatórios da publicidade.
} 
dos arranjos sociais cada vez maiores, até o ponto em que "a aceleração social se torna um sistema que se move a si mesmo". ${ }^{15}$ Os sistemas sociais funcionais (leis, ciência, política, arte etc.) tornam-se cada vez mais complexos e diferenciados, e disso resulta uma maior contingência que, por sua vez, impõe uma experiência do tempo como perpétua mudança e aceleração.

Em suma, nos três níveis citados: no plano da concorrência econômica, da promessa hedonística e da progressiva diferenciação funcional, Rosa detecta um circuito de contínua aceleração, de uma fuga para a frente desenfreada, com não poucos riscos já colocados no horizonte visível, mas aparentemente, a possibilidade de ação política que freie essa tendência está fora do âmbito da ação política e da compreensão crítica. Essa aparência de que a aceleração ocorre de forma não problemática é desfeita pela consideração de processos correlatos paradoxais, de desaceleração e, em certo sentido, de permanência e resistência.

Ou seja, ao focar a teoria crítica na questão da temporalidade e ao apontar a aceleração como um processo social abrangente que a define, Rosa $^{16}$ não deixa de chamar a atenção para a relevância de processos contíguos de desaceleração, de permanência ou de resistência à aceleração, que existem paralelamente ao aumento da velocidade. Isso é fundamental para compreender a aceleração como um conjunto de processos paradoxais, em que tanto ocorrem mudanças cada vez mais rápidas como permanecem estruturas mais amplas. Tais processos estariam relacionados a limites de velocidade naturais ou humanos, relacionados a processos fisiológicos (o tempo da gravidez, por exemplo), a nichos culturais que resistem à aceleração (os Amish), a processos de diminuição da velocidade como contrapartida da aceleração (engarrafamentos, desemprego, depressão econômica) etc. Há também desacelerações funcionais (fazer ioga para aguentar o traba-

15 ROSA (2010), p. 40. Op. cit.

16 IBID.
Iho desgastante) e ideológicas (movimentos sociais que propõem a desaceleração).

Mais fundamentalmente, Rosa ${ }^{17}$ chama também a atenção para a possibilidade de que talvez a aceleração só seja possível na medida em que exista uma orientação cultural estável ou, ainda mais essencialmente, talvez as mudanças só sejam possíveis na proporção em que permanece uma base social estável. Essa base é identificada tanto à manutenção de uma lógica industrial de produção como à permanência de instituições como a família e regimes democráticos de governo e administração centralizada. Isso não significa que o autor corrobore análises que apontam o "fim da história”, mas que ele apresenta uma compreensão de que os processos de aceleração são complementares a formas de permanência e de estabilidade, talvez tão fundamentais como as que se apresentam como aumento da velocidade, uma vez que a existência de investimentos de longo prazo - ou seja, de aceleração a longo prazo - dependem de alguma estabilidade.

O paradoxo da aceleração, então, se coloca também para a questão da reprodução social: uma ampliação desmedida da flexibilidade em grande escala, aparentemente um efeito notório da aceleração da mudança social, só é possível sobre o fundamento de certas instituições permanentes. Se tomarmos a aceleração temporal, em suas várias dimensões paradoxais, como uma modalidade de ideologia própria do mundo contemporâneo, uma discussão se destaca: a aparência de um turbilhão de mudanças cada vez mais aceleradas opera sobre uma "infraestrutura" de instituições e formas de ratio que tendem a se perenizar justamente na medida em que se produz a aceleração e a submissão da totalidade social ao tempo abstrato, isto é, às formas sociais de sujeição da vida ao modo de valorização tipicamente capitalista. O oximoro que revelava a situação cultural como ocupação da esfera da cultura pela ratio: indústria cultural, vista a situação sob a perspectiva temporal, poderia ser considerado uma imobilização acelerada.

17 ROSA (2005). Op. cit. 
Além disso, aquilo que se experiencia, no plano pessoal, dos grupos e coletividades, resulta uma aparência de fragmentação, flexibilidade, velocidade e rupturas temporais que cresce exponencialmente e, segundo seus defensores, abre um leque de total contingência, total possibilidade de escolha e abertura ilimitada do devir. Na realidade, entretanto, a ocorrência de mudanças notórias é também acompanhada de permanências, tornando a tarefa de análise, discussão e compreensão da realidade social, nesse nível, extremamente difícil, principalmente sem uma teoria unificadora. Despido de perspectivas temporais mais alargadas, sem uma tradição a que possa se referir, preso a um tempo presente abarrotado de choques sensoriais que sobrecarregam a consciência ao mesmo tempo em que bloqueiam a possibilidade de construir uma experiência sobre o que é vivido, os sujeitos se encontram em uma armadilha temporal: o incremento da celeridade resulta na paralisia das forças críticas, da autonomia, da esfera pública, da consciência.

Ao que parece, oferecer uma teoria que nos esclarece sobre esse momento do desenvolvimento das forças culturais é o maior mérito de Rosa, ${ }^{18}$ uma vez que os temas, objetos e circunstâncias a que se dedica sua análise parecem inapreensíveis, fugidios e impalpáveis apenas quando abstraída a dimensão temporal. Assim, talvez uma teoria temporal abrangente seja essencial para superar a aparência tanto de total aceleração sem freios como de imobilidade e fim da história, não porque elas sejam simplesmente falsas, pois a falsidade de conceitos ideológicos coincide com a sua pretensão de identidade à totalidade, mas porque são justamente as articulações entre o que foge e o que permanece que precisam ser compreendidas nesse momento de grande perigo.

Desse modo, é necessário tomar a relação entre passado e presente, ou entre imanência e transcendência histórica e temporal, de modo dialético, ou seja, considerar o aviso de Adorno: "a dicotomia simplista entre o

18 IBID. temporal e o eterno é conforme ao primado do universal na filosofia da história". ${ }^{19}$ Torna-se fundamental preservar a perspectiva epistemológica da dialética negativa para dar conta de identificar o mais arcaico no mais moderno, o que há de permanência nas rupturas, o que há de semelhança nas diferenças. Evidentemente, essa questão mereceria uma análise à parte; retomaremos esse tema em nossas considerações finais, mas antes, para seguir com Rosa, faremos um deslocamento para a dimensão política.

No âmago da análise da aceleração, encontra-se um problema ético-político: a capacidade humana de estabelecer para a sua vida, com liberdade e deliberação, a natureza e os fins de sua atividade. Que relação tem a dimensão temporal com a questão ética? Nesse ponto vale a pena retomar uma tese fundamental de Rosa, de modo a retirar dela suas consequências mais fundamentais.

Uma das maneiras de examinar a estrutura e a qualidade de nossas vidas é se concentrar em seus motivos temporais. Não se trata somente de que todos os aspectos da vida podem ser abordados de modo esclarecedor de uma perspectiva temporal, mas que as estruturas temporais se ligam aos níveis microscópicos e macroscópi$\cos$ da sociedade, ou seja, nossas ações e orientações são coordenadas e permanecem compatíveis com os 'imperativos sistêmicos' das sociedades capitalistas modernas através de normas, contratos e regulações temporais. As sociedades modernas são, a meu ver, reguladas, coordenadas e dominadas por um regime temporal rigoroso e estrito, que não se articula em termos éticos. Os sujeitos modernos podem, então, ser descritos como não restringidos por sanções éticas, consequentemente sendo 'livres',

19 ADORNO (2009), p. 274. 
mas sendo regidos, dominados e reprimidos por um regime temporal em grande parte invisível, despolitizado, indiscutido, não teorizado e inarticulado. Esse regime temporal pode de fato ser analisado graças a um conceito unificador: a lógica da aceleração social. ${ }^{20}$

Ou seja, o valor crítico e heurístico do conceito de aceleração é que ele procura trazer à tona todo um conjunto de "imperativos sistêmicos" temporais que operam de forma não teorizada, inarticulada, invisível, produzindo formas de dominação que os sujeitos não costumam questionar justamente porque tais imperativos não somente não são compreendidos e articulados num nível éticopolítico, mas também há entre a vivência cotidiana e a possibilidade de articulação política um fenômeno de dessincronização. Em suma: os imperativos da aceleração são inerentemente imposições sociais que operam no campo ético e político, mas não são percebidos como tais! Compreender e conceituar a dimensão temporal da vida na sociedade contemporânea é, segundo as reflexões de Rosa, uma forma de perceber o caráter necessário, inflexível, abrangente e simultaneamente arbitrário da temporalidade, o modo como, por meio de imperativos sistêmicos temporais, se impõe aos sujeitos, demandas políticas e formas de vida alienadas.

As implicações ético-políticas da aceleração são grandes e abrangem uma série de problemas institucionais e pessoais. Nesse plano, a aceleração resulta na impossibilidade de constituição do sujeito em seu sentido tradicional, moderno, como indivíduo autônomo, e isso abrange até mesmo as relações entre a consciência e o inconsciente. A aceleração dos ritmos de vida resulta em uma configuração de identidade situacional, ${ }^{21}$ entendida como processo de desconstrução dos parâmetros temporais que permitiam articular passado, presente e futuro, e assim constituir um sujeito

20 ROSA, 2010, p. 8. Tradução do autor deste ensaio. 21 ROSA, 2003. Op. cit. autônomo. Isso se expressa em mudanças nas formas de dizer a própria condição que evitam predicados identitários: deixa-se de ser católico, por exemplo, para ir à igreja católica; deixa-se de ser casado para estar com Maria.

No limite, a vida organiza-se de forma "destemporalizada", ou radicalmente "presentificada", impossibilitando traçar planos de longo prazo e acentuando a sensação de precariedade e insegurança. ${ }^{22}$ Ao lado disso, há a necessidade de constantemente ajustar-se a novas demandas, sejam tecnológicas ou organizacionais, abandonando formas conhecidas e eficazes, no plano pessoal e institucional, de funcionamento. Os níveis de insegurança e de risco tornam-se cada vez mais palpáveis, e as consequências pessoais costumam ser adoecimento, depressão e isolamento. Desenvolvem-se uma série de patologias temporais, ${ }^{23}$ assim como várias tentativas terapêuticas que tentam acomodar funcionalmente o sujeito num ambiente de incerteza e insegurança profundas.

No cerne da dificuldade relacionada ao declínio radical do indivíduo autônomo encontra-se a aceleração e sua consequência menos palpável: a perda da possibilidade de fazer experiências em relação ao mundo no plano ético e político. ${ }^{24}$ Como seria possí-

22 Situação analisada em detalhe por SENNETT (2009), que ressalta as inúmeras consequências maléficas, no plano pessoal, do trabalho na forma atual do capitalismo, e por Kehl (2015), que analisa a depressão como sintoma social em uma sociedade acelerada.

23 Destacam-se as reflexões de TÜRCKE (2012) e de BYUNG-CHUL HAN (2015), mas seria possível remeter a forma como atualmente se utilizam substâncias, lícitas ou ilícitas, à dimensão temporal, de modo a abranger um leque enorme de patologias e do sofrimento psíquico em geral.

24 O aforismo 19 da Minima Moralia ADORNO (2008) oferece um excelente exemplo de como a dimensão temporal afeta a possibilidade de produzir experiências. Nele se lê: "Entre os culpados pela morte da experiência encontra-se a circunstância de que, segundo a lei de sua pura eficácia, as coisas assumem uma forma que restringe a lida com elas à mera manipulação, sem um excedente seja de liberdade de conduta seja de tolerância pela independência da coisa, que sobreviva como germe de experiência por não ter sido consumido pelo instante da ação" ( $p$. 36). Uma vida constituída de instantes comprimidos e sobrepostos não permite o desdobramento temporal necessário à realização de experiências. 
vel a autonomia se, de um lado, o "nomos", a "lei" entendida como expressão formal de determinada ordem social - e o seu constante questionamento na esfera pública, como imaginou Kant - já não é mais palpável por se mover constantemente, por ser velozmente alterada em seu sentido. Além disso, produzir alguma experiência intelectual significativa sobre qualquer aspecto da realidade social demanda um processo de reflexão que só se realiza no tempo, com permanência, visitando constantemente o objeto em pauta; se os objetos sociais são aceleradamente transformados parece que o pensamento crítico perde os seus alvos.

Por sua vez, se demanda do sujeito que se adapte, que ajuste sua conduta e seus valores, suas ideias e seus hábitos, a uma realidade institucional em constante mudança. Os parâmetros identificadores externos deixam de existir e, sem eles, a própria identidade se vê sem substância. A única saída para o isolamento, a organização política dos trabaIhadores, se vê desprestigiada e acusada de não estar em sincronia com as novas formas de produção, comunicação e circulação de saberes e modelos organizacionais. A mudança acelerada, por fim, torna as formas democráticas de organização e decisão dessincronizadas com relação às instituições onde deveriam operar. A ação ético-política se vê bloqueada por sua natureza lenta, por estar dessincronizada com uma sociedade que só valoriza o que é veloz.

Compreendemos, assim, que a dessincronização é um dos problemas centrais, no plano ético-político, de uma sociedade em constante aceleração. Observando o que ocorre no plano da cultura, ela produz uma supressão daquilo que Habermas denominou "esfera pública" na medida em que a aceleração abrange também, em certo nível, os meios de comunicação de massas estruturados digitalmente. Já Debord ${ }^{25}$ tinha chamado a atenção para a espetacularização de todos os níveis na cultura, mas no momento em que meios de comunicação de massas dominados

25 DEBORD (1997). por grandes corporações recobrem totalmente a esfera pública, não somente todos os debates e temas são pautados por elas, mas a celeridade das notícias as desqualifica como elementos úteis ao debate ético e político. Entre outros motivos, isso ocorre porque os níveis de fragmentação, a intensidade e a imediata substituição de conteúdos uns pelos outros tornam impossível manter a atenção direcionada a determinado objeto e produzir em relação a ele uma experiência, ou ao menos, uma análise crítica.

Evidentemente, nesse sentido, pode haver uma dessincronização desejável, na medida em que o sujeito possa criar tempos alternativos, desenvolver atividades que sejam portadoras de outras formas de temporalidade em relação às demandas da cultura digital. A última reflexão nos chama a atenção para a importância que tem, em determinadas instituições como as escolas, a manutenção de espaços e períodos de temporalidade alternativa, ${ }^{26}$ não somente desacelerando em relação ao mundo da cultura digital, mas também articulando temporalidades outras, recolocando no presente elementos do passado e apontando para os efeitos futuros das escolhas que são feitas no presente.

Em suma, o que resulta da aceleração da mudança social no plano institucional, segundo Rosa, ${ }^{27}$ é um conjunto de paradoxos. Uma vivência destemporalizada e a contração do presente são expressões deste problema: a uma aceleração dos eventos corresponde uma desaceleração da capacidade humana de atribuir sentidos e atuar politicamente. Os imperativos sistêmicos no âmbito temporal se revelam mais um exemplo - ou uma nova dimensão - da ordem social autonomizada em relação aos homens, ou seja, do que Marx denominou "o capital" - uma forma de sociabilidade humana que se torna alienada em relação aos homens. A aceleração seria, então, uma atualização do diagnóstico do estranhamento (entfremdung) descrito por Marx,

\footnotetext{
26 Tal como, em certo sentido, propõe TÜRCKE (2016) com sua disciplina de estudos rituais.

27 ROSA (2003). Op. cit.
} 
e seu desvelamento apontaria para a nova modalidade específica da ideologia, ou seja, de justificativa para as atuais formas de dominação. Se os sujeitos não podem mais refletir a respeito do seu trabalho, sobre a origem e a finalidade da sociedade, perdemos a nossa liberdade, embora as expectativas hedonistas cresçam em relação direta com a maior oferta de mercadorias espetaculares.

\section{CONSIDERAÇÕES FINAIS}

A existência humana é um processo temporal, em qualquer forma de ordem social, mas os imperativos sistêmicos relacionados à aceleração produzem formas de dessincronização e contração do presente, que geram uma série de problemas: as fronteiras temporais entre trabalho e lazer, público e privado, passado e futuro se veem perigosamente negadas, com um enorme prejuízo para a possibilidade de fazer operar de forma democrática a chamada "esfera pública"; as novas tecnologias de comunicação alcançam os sujeitos em qualquer lugar e a qualquer hora, intensificando o trabalho e soterrando a consciência sob uma avalanche de estímulos de enorme intensidade, que bloqueiam a possibilidade de produzir experiências, ou seja, tornando a vida desarticulada temporalmente, com consequências drásticas, tanto no plano pessoal como social; ideais sociais alienados, como a "fome temporal" e os ideais hedonísticos, instigam o sujeito a acelerar suas ações, a produzir mais e até mesmo a expor - num ambiente concorrencial - sua "personalidade" como mais um atributo que o valoriza, rompendo a delicada articulação entre o mundo interno e externo, entre espaços privados e a vida pública, culminando na supressão da individualidade justamente pela aparência de sua entronização. Finalmente, sem parâmetros históricos, preso a um presente contínuo e contraído, o sujeito se vê isolado e incapaz de questionar os rumos que toma a sociedade.

Assim, compreende-se a dispersão teórica sobre como conceituar a era contemporânea; a dificuldade, ao menos em um sentido, provém da configuração temporal em que estamos imersos, que recusa uma definição abrangente a partir de aspectos específicos, uma vez que "tudo o que é sólido se desmancha no ar", como pontuavam Marx e Engels no Manifesto Comunista. Mas, ao colocar em pauta a temporalidade, a forma específica de construção social do tempo, Rosa nos apresenta o cerne do problema: a forma temporal contemporânea é essencialmente paradoxal, de modo que sua melhor expressão é a aceleração, mas ela mesma é uma espécie de paralisia e de recorrência de formas sociais alienadas.

Evidentemente, o que as reflexões atuais que dialogam com a tradição da Teoria Crítica apontam é que essa configuração temporal acelerada tem configuração específica na chamada cultura digital, influenciando a formação da subjetividade e a esfera pública. Vivemos em um constante déficit ético e político por motivos que abrangem tanto a semiformação socializada e as patologias temporais que se manifestam no plano subjetivo, como pela ocupação sistemática e ubíqua da esfera pública pela lógica do espetáculo.

Mas o aspecto mais interessante dos conceitos temporais elaborados por Rosa é que eles levam ao reconhecimento do caráter ambíguo, paradoxal, da temporalidade alienada contemporânea e de suas inúmeras fissuras. As formas de dessincronização que acompanham os processos de aceleração, por exemplo, nos chamam a atenção também para as possibilidades de resistência e mudança relacionadas à criação de momentos não alinhados aos imperativos da aceleração. Só para indicarmos uma possibilidade banal, quem se dedica à leitura de um romance coloca-se em um mundo temporal paralelo, relativamente distanciado das demandas temporais aceleradas, e tem a chance de se colocar em uma posição crítica com relação ao tempo alienado.

Além disso, é cada vez mais notório que o processo social de aceleração gera problemas estruturais gravíssimos, atingindo limites naturais que ameaçam o meio ambiente, a saúde e o bem-estar dos seres humanos e o mero bom senso. Apesar do debate demo- 
crático estar "dessincronizado" com os imperativos temporais da sociedade acelerada, é sempre importante lembrar que a sociedade é uma organização humana, temporal, isto é, aberta a outras possibilidades e como tal, passível de ser alterada. O reconhecimento dos imperativos temporais sistêmicos em seus vários âmbitos é importante para nos tornarmos mais capazes de nos organizar e resistir.

\section{REFERÊNCIAS}

ADORNO, T. W. Dialética Negativa. Rio de Janeiro: Jorge Zahar Ed. 2009.

ADORNO, T. W. Minima Moralia: reflexões a partir da vida lesada. Rio de Janeiro: Beco do Azougue, 2008.

BECK, U. Liberdade ou Capitalismo: Ulrich Beck conversa com Johannes Willms. São Paulo: Editora Unesp, 2003.

HARVEY, D. Condição Pós-moderna: uma pesquisa sobre as origens da mudança cultural. São Paulo: Edições Loyola, 2004.

JAMESON, F. Modernidade Singular: ensaio sobre a ontologia do presente. Rio de Janeiro: Civilização Brasileira, 2005.

KEHL, M. R. O Tempo e o Cão: atualidade das depressões. São Paulo: Biotempo, 2015.

POSTONE, M. Tempo, Trabalho e Dominação Social: uma reinterpretação da teoria crítica de Marx. São Paulo: Boitempo, 2014.

ROSA, H. Social Acceleration: Ethical and Political Consequences of a Desynchronized Highspeed Society. In: Oxford, UK, Constellations, vol. 10, nº. 1, p 3-33, 2003.

ROSA, H. Aliénation et Accélération: vers une théorie critique de la modernité tardive. Paris: La Découverte, 2005.

ROSA, H. Accélération: une critique sociale du temps. Paris: La Découverte, 2010.

SENNETT, R. A Corrosão do Caráter: consequências pessoais do trabalho no novo capitalismo. Rio de Janeiro: Ed. Record, 2009.

TÜRCKE, C. Sociedade Excitada: filosofia da sensação. Campinas, SP: Editora da Unicamp, 2010.

TÜRCKE, C. Hiperativos: abaixo a cultura do déficit de atenção. São Paulo: Paz e Terra, 2016.

\section{DADOS DO AUTOR}

\section{ARI FERNANDo MAIA}

Doutor em Psicologia pela Universidade de São Paulo. Professor do Departamento de Psicologia da Faculdade de Ciências, Unesp - Bauru e do Programa de Pós Graduação em Educação Escolar da FCLar, Unesp - Araraquara. Bauru/SP - Brasil. arimaia@fc.unesp.br

Submetido em: 10-4-2017

Aceito em: 21-6-2017 